\title{
EXPERIÊNCIAS PEDAGÓGICAS DE UM CURRÍCULO EM MOVIMENTO NO ENSINO MÉDIO EM TERRITÓRIO RURAL
}

Adelson Dias de Oliveira

Jane Adriana Vasconcelos Pacheco Rios ${ }^{(*)}$

\section{DA APROPRIAÇÃO AO MOVIMENTO DA EXPERIÊNCIA CURRICULAR - UM PONTO DE PARTIDA}

\begin{abstract}
Os diversos espaços e tempos de formação apresentados pelos jovens, em suas narrativas, apontam para a necessidade de inclusão e/ou ressignificação dos modelos que vigoram nas diversas práxis, especialmente no ambiente educacional institucionalizado, rompendo com a barreira dos currículos estagnados e transformando-os em elementos vivos, fazendo-o significar para a formação e a prática futura dos jovens numa sociedade que muda constantemente. (OLIVEIRA, 2014, p. 125).
\end{abstract}

Decidimos começar este diálogo pela provocação apontada na epígrafe, por considerar que esse seja o pontapé para o alicerçamento das questões se configuram ao longo do texto. É da provocação emanada nas narrativas de jovens que vivem nos espaços das ruralidades e das vivências pessoais e profissionais que o estudo toma forma.

Vale ressaltar, que o olhar para o ensino médio surge como um elemento que merece atenção no que consiste ao que se trata de experiências curriculares e processos formativos, que possibilitem a condição de desenvolver as competências necessárias para a vida profissional dos nossos jovens, bem como a sua relação com o outro, a dimensão humana e social que é intrínseca ao ser humano.

Destarte, é intrigante como nas sociedades contemporâneas é comum não serem consideradas as particularidades dos sujeitos em detrimento a homogeneização oriunda do processo de globalização, se tornando uma prática que se fez comum no mundo contemporâneo. Estamos a todo momento adjetivando as coisas, as pessoas, os lugares e tudo que nos envolve.

Construímos constantemente julgamento de valores que passam a impetrar e incidir diretamente na forma em que as pessoas passam a conduzir suas vidas, especialmente se ainda é jovem. Cada dia que se passa as portas sociais são afuniladas e obrigam as pessoas na

\footnotetext{
${ }^{(*)}$ Adelson Dias de Oliveira. UNIVASF/ PPGEduC - UNEB. E-mail: adelsonjovem@ gmail.com. Jane Adriana Vasconcelos Pacheco Rios. PPGEduC/UNEB. E-mail: jhanrios1@ yahoo.com.br.
} 
contemporaneidade a serem subjugadas e envolvidas numa trama que o faz afastar-se de si para se aproximar dos interesses impostos socialmente como forma de atuação e participação social

Assim, o ponto de partida para a escrita deste texto, situa-se na concepção de currículo vivido e experienciado, que está para além da prescrição e execução de uma proposta que não apresente sentido para professores e alunos que estão envolvidos no movimento da construção de conhecimento.

Não pretendemos fazer aqui uma longa discussão sobre a teoria curricular que ao longo dos anos vem se desenvolvendo. A proposta é trazer apontamentos da experiência da docência em escolas em território rural ao se desenvolver o ensino e vivência curricular junto aos alunos que estão localizados neste lugar. Como estes professores que vivem na cidade, estão vinculados a uma escola urbana se apropriam e exeprienciam o fato de desenvolver um currículo que traz todas as marcas hegemônicas e urbanocêntricas para o espaço das ruralidades? Esta tem sido a indagação principal e para a escrita deste trabalho, o termo apropriação e experiência curricular tomam centralidade e desencadeiam o processo reflexivo e constitutivo.

Por que tratar de apropriação curricular no ensino médio e de maneira particular para escolas em territórios rurais? Bem, esta vinculação se dá particularmente por conta de todo o movimento de reforma curricular vivida no Brasil e que ao se constituir produz efeito direto no formato em que este se desenvolve nos espaços de ruralidades, espaços estes constituídos de características muito singulares que vão desde o movimento de negação ao que chamamos de homogeneização e conhecimento básico e sem vinculação com o que vivem estes sujeitos.

São estes elementos que nos aproximam do que propõe Stenhouse (2003) ao vincular a conceituação de currículo ao processo de experimentação e construção de conhecimento e do ensino como elementos que se complementam. Aproxima-se do sentido que é dado ao desenvolvimento deste currículo e desta maneira como o conhecimento é produzido. Todavia, é pertinente ressaltar que de maneira vívida se percebe ao longo do que se faz nas escolas um processo pragmático da vivencia curricular.

Tal forma de viver o currículo nas escolas em território rural é uma prática comum no que diz respeito ao formato em que o ensino para estudantes do ensino médio vai se constituindo. Existe um movimento de reprodução e replicação de estruturas já dadas e deslocadas do contexto em que os jovens vivem e por conseguinte dão conta de validar o que Apple (1997) aponta como a validação de elementos culturais, econômicos e sociais que estão involucrados na concepção de 
sociedade contemporânea e esta perspectiva é redimensionada para o espaço educativo e por conseguinte gera um sistema de formação unilateral.

Acreditamos que para romper com tais situações, de maneira distinta para a escolas localizadas em territórios rurais, a apropriação do currículo não apenas como um conjunto de conteúdos e sequencias a serem seguidas com o fim único de transmissão de conhecimento, se constitui como possibilidade de elaboração de uma nova perspectiva no que tange aos aspectos inerentes ao ensino e as práticas curriculares.

Se propõe reflexionar o espaço de atuação curricular como elemento de apropriação social e que seja construído de maneira que a experiência possa ser ressaltada no movimento de sua constituição, passando-se a apropriar-se de tal forma que se construam novas dinâmicas no espaço educativo.

Em se tratando do movimento de reforma curricular que perpassa e interpela a sua concepção na contemporaneidade Suárez sinaliza que

Ya sea porque los operativos de reforma educativa emprendidos en las últimas décadas
tuvieron o tienen como uno de sus ejes fundamentales la actualización de los contenidos
escolares, o bien porque los analistas y técnicos del campo educativo han generado todo un
terreno profesional y un saber especializado en torno a los procesos de selección, organización
y distribución de esos contenidos, la "cuestión curricular" se fue constituyendo en un capítulo
insoslayable de las agendas de políticas públicas y de discusión en torno a la escolaridad (2000,
p. 97).

Mediante estas perspectivas em que se pensa e pauta o currículo, é que este texto se debruça se constitui. Tomamos como ponto nodal o lugar da experiência enquanto território vivido e experienciado por docentes que atuam nos espaços das ruralidades.

É deste lugar que nasce o que estamos chamando de currículo em movimento. A atuação nas escolas localizadas nas ruralidades, geralmente, ocorre por docentes que vivem em áreas urbanas e se deslocam cotidianamente para desenvolver sua prática profissional e se apropriam de um currículo com o desenho urbano e o tomam de um outro lugar, num outro contexto.

O desafio em que este texto se propõe, está na reflexão especifica do lugar desse currículo apropriado ou não por estes docentes em movimento num cenário de reforma curricular para o ensino médio e por conseguinte se pensar a dinâmica da escola vivida nas ruralidades. E, desta forma adentramos a perspectiva de Goodson (1991) ao tratar de currículo como conflito social, elementos que pretendemos apresentar ao longo ou mediados pelas discussões que se seguem ao longo do texto. 


\section{UM CORTE! UMA PAUSA PARA SEGUIR: BREVE REFLEXÃO METODOLÓGICA}

Antes de avançarmos no debate sobre a temática elucidada até então, vale ressaltar que este trabalho é resultado de aproximações e leituras conceituais no campo da teoria de currículo e está vinculado a experiência de investigar a experiência pedagógica e curricular de professores que atuam em escola localizadas em território rural da cidade de Juazeiro na Bahia/Brasil.

Enquanto corpus metodológico, se configura como uma pesquisa de enfoque qualitativo, que toma como princípio a abordagem (auto)biográfica (SOUZA, 2006) aliada as perspectivas da etnografia na educação (ANDRE, 2012). Utilizamos a observação e documentação narrativa de experiência pedagógica (SUÁREZ, 2005) como dispositivos de recolha das narrativas dos sujeitos, onde os professores poderão contar a experiência de levar à prática uma proposta curricular em "trânsito". Para analisar, as narrativas, elegemos a triangulação de fontes vinculada aos princípios da hermenêutica.

Desta forma, vale considerar que por intermédio das experiências de formação que seja trazido à tona os aspectos inerentes a constituição desse processo constitutivo na relação que faz pelo docente na prática a partir dos momentos de formação e dessa maneira reverbera na ação educativa dos sujeitos, aqui no caso, os jovens estudantes de escolas do ensino médio em territórios rurais. Com tais dimensões corroboramos com a assertiva,

[...] falar de si torna-se uma tarefa não muito fácil, pois envolve um processo de rememorizar e reviver momentos que fizeram parte da vida do sujeito. A fala do sujeito que narra pode vir repleta de aspectos voltados para a emoção e hesitações, por sua vez, o estudioso de história de vida encontra desafio em extrair da enunciação informações disponibilizadas e aspectos que desvelem e estão presentes no cotidiano da sociedade que permitam a sua compreensão. (OLIVEIRA, 2014, p. 22).

A autobiografia aqui então utilizada como abordagem teórico-metodológica, possibilita ao autor construir uma relação direta com o seu objeto de estudo, todavia, esse processo (auto)biográfico se constrói a partir da dimensão da experiência que os sujeitos narradores constroem em face ao fazer pedagógico e sua relação com os estudantes, de maneira singular numa territorialidade do que os espaços educativos nas ruralidades possibilitam.

Vale considerar que o diálogo direto com a dimensão da biografia do e da história de vida como perspectivas metodológicas, bem como uma abordagem teórico-metodológica (auto) biográficas, tem sido a dimensão pela qual tomo referência para a realização da pesquisa. Deste modo, 
A revalorização das autobiografias instaura-se no campo da história social, especificamente, com a "viragem" e contribuições teórico-epistemológicas da história cultural (CHARTIER, 1990) e seu interesse pelo cotidiano, o pessoal, o privado, o familiar e suas representações e apropriações, seja na história da educação seja em outros campos educacionais, a partir do estudo da história do currículo, das reformas educativas, das práticas e culturas escolares, da feminização da profissão, do processo de profissionalização e das práticas docentes. (SOUZA, 2006, p. 24-25).

Tomar o campo da autobiografia como elemento norteador para desenvolver o trabalho de campo tem no corpo desta pesquisa a centralidade. Todavia será inscrita ainda no processo metodológico como elemento que alia na construção do conhecimento e a obtenção de aspectos que possibilitem a realização da análise, a inserção da etnografia do cotidiano escolar como elemento agregador ao processo de construção da pesquisa, fazendo aí uma aproximação da etnografia ao campo da educação. Para tanto é pertinente sinalizar a contribuição de André (2012, p. 41), ao dizer que "A pesquisa do tipo etnográfico, que se caracteriza fundamentalmente por um contato direto do pesquisador com a situação pesquisada, permite construir os processos e as relações que configuram a experiência escolar diária".

A vinculação do trabalho etnográfico a abordagem autobiográfica constitui-se como um conjunto de ações que possibilitará a entrada no campo da pesquisa, a imersão nas subjetividades dos sujeitos e do lugar e a possibilidade de interação com os resultados que a pesquisa produzirá, mediados pelo rigor e pela cientificidade necessária ao desenvolvimento do estudo.

Propomos a utilização do registro das experiências pedagógicas, tomando como princípio a proposta da Documentação Narrativa de Experiências Pedagógicas, inspirada nos trabalhos desenvolvidos por Daniel Hugo Suárez através do Grupo Memória Docente y Documentación Pedagógica de la Facultad de Filosofia y Letras de la Universidad de Buenos Aires (UBA),

Al recuperar, interpretar y recrear los saberes prácticos que los docentes producen a través de su ejercicio profesional, los diversos trayectos de formación de maestros y professores que se diseñen y desarrollen se encontrarán íntimamente informados y relacionados com la diversidad, heterogeneidad y complejidad de la enseñanza escolar. (SUÁREZ, 2005, p. 9).

Considerando que a Documentação Narrativa de Experiência Pedagógica e Educativa dos docentes possibilita fazer a retomada de suas práticas por intermédio do seu registro, está se alia diretamente aos dispositivos utilizados anteriormente, uma vez que convergem para que o narrador possa construir sua narrativa de maneira a produzir em conjunto com um processo de reflexividade e dialogicidade com as dinâmicas do seu cotidiano. 


\section{O ENSINO MÉDIO, A REFORMA E COMO PENSAMOS CURRÍCULO NAS RURALIDADES}

Num contexto de reformas educacionais, surgimentos de novas concepções acerca da teoria de currículo e da relação dos espaços educativos com a lógica e interesse sociais, fazemos um recorte para localizar o trânsito conceitual em que estamos vinculados ao longo deste texto.

Somente no início do século XXI, a educação e, como ela é praticada torna-se objeto de estudo e alvo de ações políticas mais efetivas, todavia, não foge a lógica excludente e determinista com a qual a história da educação no Brasil foi se constituindo. Como se não bastasse, toda a influência de um período colonizador e opressor é visível nas práticas, nos currículos e na organização do sistema educacional do país. É pertinente assinalar que tais elementos estão muito mais visíveis na separação da educação que é levada para a cidade e para os territórios rurais, ou melhor, na subjugação deste lugar, em face ao desenvolvimento de práticas educativas e curriculares completamente hegemônicas e urbanocêntricas. Com este intento, destacamos aqui o que escreve Apple ao tratar de currículo,

La forma de organizar el currículum, los principios sobre los que se basa y evalúa, el verdadero conocimiento, todo ello era muy importante si se quería entender cómo se reproduce el poder. Y aquí no me refiero sólo al poder económico, sino también al cultural, aunque los dos estén inter-relacionados en gran medida. (1997, p. 36).

Reforça dessa forma a perspectiva de que todos os traços culturais estão intimamente presentes nas práticas curriculares desenvolvidas nas escolas do campo, e ampliam-se elementos das relações de poder que se constituem ao desenvolver e se relacionar o processo educativo no território rural e a oferta da Educação Básica do Semiárido brasileiro.

Nesse sentido, o ambiente educativo e a apropriação do que está prescrito, se constroem com base em um currículo em que tradicionalmente não considera as particularidades e o contexto local, voltadas para a reprodução de conhecimentos e saberes impostos, por meio de livros didáticos inadequados, como verdades absolutas "consumidas" pelos alunos sem qualquer processo de reflexão crítica acerca dos significados e valores do que lhes é imposto para as suas vidas (LIMA \& OLIVEIRA, 2010).

Como um dos marcadores na experiência de formação desses sujeitos, a escola tem grande destaque, especialmente a experiência docente e toda a sua relação com o cotidiano vivenciado pelos jovens que estão vinculados ao ambiente escolar do ensino médio ofertado em territórios rurais. 
As experiências curriculares e pedagógicas em que estes professores vivenciam estão marcadas por uma temporalidade e formato de desenvolvimento diferenciado do que se faz nas escolas da cidade. É perceptível desta maneira que a manifestação do distanciamento das falas e das práticas dos professores pode ser considerada como uma luz de alerta que se acende no campo educacional em relação ao processo de ensino-aprendizagem e à absorção de jovens com identidades distintas e vivências específicas. Relacioná-la com o contexto atual nos remete, também, analisar as mudanças ocorridas ao longo dos últimos anos na escola e no fazer pedagógico pelos docentes.

Nesse sentido, Reis (2011) expõe que a escola precisa ser espaço que vai além da garantia do acesso à educação aos filhos de "camponeses"- tratando da educação do campo -, como local também de conhecimento contextualizado e de significado para as suas vidas. Nessa direção, é pertinente considerar que, nos últimos anos, observam-se mudanças significativas no processo ensino-aprendizagem e da forma como as experiências pedagógicas são vivenciadas pelos docentes. Não obstante, voltando-se para o que se concebe enquanto currículo é pertinente considerar que

La política curricular parte así de un marco de definiciones básicas que permiten modelaciones particularizadas a medida que se realiza en contextos educativos concretos, obligando de alguna forma, por la necesidad misma que plantea ese proceso de concreción, a que todos los que tienen alguna responsabilidad en la decisión y en la realización del proyecto tengan que participar activamente. Se convierte así el proceso del desarrollo del curriculum en un marco estimulante de energías creadoras y de compromiso de los profesores en la traslación y realización del curriculum. Por ello, la política y el «formato» curricular es un factor potencial decisivo de la renovación pedagógica, un instrumento de formación de profesores y un determinante de la calidad de la educación. (SACRISTÁN, 1991, p. 1).

Tais questões apontam para se pensar uma escola que dialogue com as perspectivas e anseios que os jovens sinalizam para seu projeto de vida. O ensino médio aqui compreendido não apenas como o momento de finalização da fase de escolarização, mas como o espaço de mediação entre o que vive e aquilo que será tomado como futuro em vida.

Considerar os estilos de vida, os valores e práticas sociais presentes nas distintas gerações que fazem parte do cotidiano do ensino médio, como apontam as Diretrizes Curriculares do Ensino Médio (DCEM), é um elemento fundante para se estabelecer laços com a pretensão de oferecer educação significativa.

As justificativas para elaboração de novas diretrizes curriculares para o ensino médio estão anunciadas no parecer CNE/CEB 05/2011 e dizem respeito a mudanças recentes na legislação e política educacionais, tais como a criação do Fundo de Manutenção e Desenvolvimento da 
Educação Básica e de Valorização dos Profissionais da Educação (FUNDEB) e a ampliação da obrigatoriedade da escolarização. De acordo com as novas diretrizes curriculares para o ensino médio,

O desencaixe entre a escola e os jovens não deve ser visto como decorrente, nem de uma suposta incompetência da instituição, nem de um suposto desinteresse dos estudantes. As análises se tornam produtivas à medida que enfoquem a relação entre os sujeitos e a escola no âmbito de um quadro mais amplo, considerando as transformações sociais em curso. Essas transformações estão produzindo sujeitos com estilos de vida, valores e práticas sociais que os tornam muito distintos das gerações anteriores. Entender tal processo de transformação é relevante para a compreensão das dificuldades hoje constatadas nas relações entre os jovens e a escola. (BRASIL, 2011, p. 13).

Articular a necessidade de redimensionar o ensino médio no Brasil para atender as demandas contemporâneas tem relação direta com a necessidade de considerar os aspectos contextuais em que a globalização tem forte influência, especialmente, no tocante a dimensão das ruralidades. A dimensão de olhar as ruralidades como uma ação contra-hegemônica requer também o pensamento de uma existência a partir das relações com algo que significa a cultura, como nãorural, outros contextos sociais que estão presentes no espaço e no tempo de desenvolvimento das ruralidades (MOREIRA, 2005). Nesse ínterim cabe a dimensão do extrapolar os estereótipos presentes no imaginário social constituído ao longo da história.

A ressignificação do rural como espaço singular, porém com atos coletivos e de construção histórica num espaço diversificado é um desafio constante. A interpretação do lugar do atraso e ligado apenas a natureza é uma constante. Ao narrar que o trabalho no rural é a realização de um desejo forte, verbaliza também uma dimensão subjetiva de como percebemos o nosso contexto, às vezes influenciável pelas informações massificadas e que constroem uma visão homogênea do que o lugar, que dificulta a ampliação do olhar para a dimensão do que de fato é o lugar. Outro aspecto, que merece atenção é o fato de apontar a dimensão do conhecimento superficial e a reprodução desse conhecimento, sendo uma preocupação grande para em especial quando se trata de trabalhar com o público jovem do ensino médio.

Arroyo (2014, p. 54), provoca-nos a construir uma nova dimensão de ensino médio, nos fazendo refletir

[...] quando as escolas, os coletivos docentes e até as Diretrizes Curriculares do CNE se propõem repensar os currículos do Ensino Médio - perguntar-nos que práticas inovadoras estão acontecendo nas escolas, nas diversas áreas do conhecimento. Se o conhecimento é um campo dinâmico, o currículo não pode ser reverenciado como um campo estático, mas como um território de disputa no que diz respeito à forma como o próprio conhecimento é 
disputado na sociedade. Trata-se de reconhecer o currículo, na prática, como um território de saberes e incertezas. (Grifo dos autores)

A dimensão curricular em que o ensino médio se pauta deve proporcionar a produção de conhecimento que seja significativo, fazer isso na lógica curricular vivida no nosso país é de fato evidenciar os territórios de disputas, que toma forma de aspectos que não são claros e denotam a marca colonizadora e hegemônicas existente nas práticas educacionais do nosso país, de forma particular no campo das ruralidades. As questões de "saber" são tomadas como primordiais para o processo de aprendizagem e de significação.

Vale ressaltar que neste universo de mudanças não se deixa de lado a Diretriz Operacional da Educação Básica no Campo 01/2002 que propõe a oferta de toda a educação básica, incluindo aí a dimensão do ensino médio para o público residente no campo. Destarte, surge o questionamento de como acontece esse deslocamento da sala de aula do ensino para o campo, quais mudanças curriculares são evidenciadas para atender as demandas específicas dos sujeitos jovens que ingressam nessas aulas?

O questionamento apresentado provoca uma abertura que se insere os aspectos da dinâmica construída por docentes e alunos no universo das escolas em territórios rurais. A adaptação aos tempos e os espaços disponibilizados para que as aulas ocorram, vão dando lugar a um processo de apropriação e reconstrução do saber mediado pelo deslocamento que se faz dos aspectos diversos da aprendizagem simultânea que se constroem nas experiências pedagógicas e curriculares partindo desse lugar e dessa vivência.

Sendo este o movimento necessário para que a apropriação curricular ocorra e vá para além da legitimação do poder em detrimento aos problemas e conflitos sociais culturalmente constituídos. É o lugar da desconstrução e da reapropriação.

\section{APROPRIAÇÃO, REAPROPRIAÇÃO, CONSTRUÇÃ̃O OU REPRODUÇÃO: A EXPERIÊNCIA DE UM CURRÍCULO DESLOCADO E EM MOVIMENTO.}

Apropriando-se do pensamento de Arroyo (2014), o currículo não pode ser concebido com algo estático e sem movimento ou transformação, requer tensionamentos constantes para que emerjam aí as possibilidades de se construir novas maneiras de vivenciar a escola, mediante os elementos que constituem social e culturalmente o campo educacional.

Nesse sentido é pertinente a entrada de dois núcleos de sentido extremamente significativo para aproximarmo-nos do que propõe este texto. A experiência como território vivenciado e 
articulado na ação docente e os deslocamentos curriculares advindos dos tensionamentos que fazem parte de suas práticas. Todas essas questões sob um olhar direcionado para o modo em que estas temáticas passam a se constituir como significativas e incidir diretamente nos processos construídos por estes sujeitos.

Estes aspectos estão vinculados a presença de elementos históricos, culturais e sociais que se entrecruzam no processo de formação dos sujeitos e tais questões vão produzindo novas dimensões de experiência, nesse caso para os professores com o que se vincula a sua vivencia pedagógica e curricular.

Ao longo da discussão estamos vinculando sempre o debate sobre o desenvolvimento de um currículo em escola localizada em território rural, porém, que possa também atender as demandas da política de educação do campo que vem se constituindo ao longo das três últimas décadas (final do século passado e deste século). O currículo a que nos referimos está vinculado diretamente as experiências dos docentes no seu processo de apropriação e deslocamento do currículo prescrito e construído com caráter urbanocêntrico.

Assim, percebemos que saltam aspectos de um curriculum construído atualmente para atender a necessidades de um mundo globalizado, numa dimensão homogênea, porém os contextos revelam outras necessidades e tempos de experimentação. A oferta de ensino médio em territórios rurais, demarcado pelo desenvolvimento, deslocamento e experiências curriculares em que os professores passam a viver numa dimensão prática pode constituir um novo jeito de se viver esse currículo.

Vale ressaltar que neste universo de mudanças não se deixa de lado a Diretriz Operacional da Educação Básica no Campo 01/2002 que propõe a oferta de toda a educação básica, incluindo aí a dimensão do ensino médio para o público residente no campo. Destarte, surge o questionamento de como acontece esse deslocamento da sala de aula do ensino para o campo, quais mudanças curriculares são evidenciadas para atender as demandas específicas dos sujeitos jovens que ingressam nessas aulas?

Ressaltamos aqui que na experiência da Bahia, a oferta de ensino médio para jovens que vivem em territórios rurais está distribuída em algumas modalidades. A intermediação tecnológica, que ocorre via transmissão de satélite desde a cidade de Salvador/BA para as escolas localizadas no interior da Bahia, em que um professor intermedia o processo junto aos alunos. A segunda maneira é ainda através do telecurso 2000, em que a aprendizagem ocorre mediante a exibição de aulas gravadas e o professor apenas exibe e proporciona um espaço de conversação. E a última, que aqui 
é o foco, é a oferta em anexos, que são espaços cedidos por escolas municipais localizadas em territórios rurais em que os professores se deslocam da cidade para desta maneira desenvolverem suas aulas junto aos alunos de ensino médio.

A presença dos anexos para o ensino médio no campo é um intrigante espaço de estudo por denotar uma possibilidade de inserção do ensino para os jovens sem a necessidade de deslocá-los para a cidade, todavia, se faz necessário perceber como esse ensino chega aos alunos. Existe uma vinculação do ensino com o lugar a significação do saber ou apenas o encurtamento do caminho em que esses jovens fazem? Ao invés de irem para a cidade, essa leva os seus preceitos e organização para o campo?

Ocorre um deslocamento dos docentes do espaço urbano para o território rural, da mesma forma que também se desloca o currículo, todavia a apropriação e a experiência destes docentes com o desenvolvimento curricular num contexto de campo é algo que provoca a construção de entendimentos sobre a experiência pedagógica docente e sua relação com a formação de jovens em territórios rurais.

Cabe então, um destaque para a relação que se estabelece entre o professor e o aluno, nesse caso, o jovem, no âmbito do ensino médio e o desenvolvimento de suas experiências pedagógicas.

[...] Há um avançar tenso de reinvenção da docência e dos currículos como resposta ao precário e injusto viver dos novos educandos e educandas que acedem à educação média. Que experiências sociais vivem, que indagações e que leituras levam às escolas sobre seu viver, sobre a sociedade, a cidade, o campo? (ARROYO, 2014, p. 58).

E neste campo implica a concepção de que o desenvolvimento do currículo que é vivido no ambiente educacional do campo corresponde a processos determinados por processos sócio históricos em que os conteúdos são selecionados, dispostos e transmitidos pela escola (SUÁREZ, 2000).

A experiência de um currículo em movimento começa exatamente com o deslocamento físico e didático que estes nove professores fazem para que as aulas possam acontecer. $\mathrm{O}$ deslocamento que fazem também se localiza na construção de uma perspectiva curricular em que estes se apropriam e desenvolvem de acordo outras dimensões que estão para além do que se faz ao trabalhar na mesma escola no espaço urbano. Por isso acreditamos que estas questões dialogam diretamente com o que aproxima Stenhouse (1991, p.11), "Un curriculum, si es valioso, expresa en forma de materiales de enseñanza y criterios para enseñar una visión del conocimiento y una concepción del proceso de educación". 
A ideia de que estes professores se apropriam de uma perspectiva curricular a as desenvolvem de acordo com suas experiências está vinculada ao observado ao longo de dois meses. Vinculam a estrutura ofertada pela escola e o que dispõem de conhecimento e suporte técnico a suas experiências pedagógicas e vão reconstruindo as dimensões educativas presentes naquele lugar.

\section{CHEGAMOS ATÉ AQUI: ASPECTOS DE UMA CONCLUSÃO PONTUAL}

Acreditamos que os territórios rurais possuem características distintas, porém, com similaridades possíveis para serem tecidas mudanças significativas nos ambientes diversos. É esse movimento de alteridade que permitirá aos sujeitos ali implicados a possibilidade de discernir e construir novos entendimentos e possibilidades de viver.

Os jovens vivem esse movimento de forma intensa ao construírem desde muito cedo um movimento migratório que vai se consolidando aos poucos, o deslocamento diário do seu lugar para os centros urbanos ou para os distritos urbanizados nos territórios rurais, implicam uma dimensão de desterritorialização para a reconfiguração desse espaço em seu conjunto de características, vivências e possibilidade e dessa maneira passam a constituir para si um novo território, uma nova dimensão de ruralidade por eles vivenciadas. Consideramos que tais mudanças estão localizadas no campo dos deslocamentos do simbólico e materiais de maneira constante.

Diante do exposto, propomos avançar para a discussão do direito à educação básica integral e de qualidade no campo. Uma vez que, a centralidade do estudo tende para as questões de experiências e práticas de docentes e jovens no campo do ensino médio em territórios rurais. É sabido que mesmo diante de políticas públicas claras que evocam a oferta de todos os níveis e modalidades da educação básica no campo, de maneira prática não é visível.

No tocante às políticas públicas, o acesso e a participação, onde cabe certamente a oferta do ensino médio de qualidade para as juventudes, de maneira enfática para os jovens de territórios rurais. Evidenciamos aqui especialmente as possibilidades de participar das políticas e os direitos aos jovens, que são negados na sociedade em que vivemos na contemporaneidade, por resquícios de construções históricas.

Não reforçar a ideia de jovem como um “vir a ser adulto". É salutar considerar a presença de problemas sociais também no campo e vivenciados pelos jovens que lá residem. Os jovens que estão no ensino médio ainda não possuem maioridade, entra o conflito entre a discussão sobre juventude e adolescência, Dayrell e Carrano (2014) tratam a adolescência como a primeira fase da 
juventude, interagindo com conceitos da sociologia e antropologia que vincula estes sujeitos aos processos sociais e responsabilidades assumidas.

Por fim, ocorre um deslocamento dos docentes do espaço urbano para o território rural, da mesma forma que também se desloca o currículo, todavia a apropriação e a experiência destes docentes com o desenvolvimento curricular num contexto de campo é algo que provoca a construção de entendimentos sobre a experiência pedagógica docente e sua relação com a formação de jovens em territórios rurais, sendo este o aspecto que nos provoca a seguir o estudo e involucrar novos questionamentos para pesquisa. 


\section{REFERÊNCIAS}

André, M. E. D. A. Etnografia da prática escolar. 18. ed. Campinas, SP: Papirus, 2012.

Apple, M. W. Educación y poder. Centro de Publicaciones del Ministerio de Educación y Ciencia, Ciudad Universitária. Barcelona: Paidós Ibérica S. A. 1997.

Arroyo, M. Repensar o Ensino Médio: Por quê? In: DAYRELL, J.; CARRANO, P.; MAIA, C.L. (Orgs.) Juventude e ensino médio: sujeitos e currículos em diálogo. Belo Horizonte: Editora UFMG, 2014.

Brasil. Conselho Nacional de Educação.. Parecer CNE/CEB n. 5/2011. Diretrizes Curriculares Nacionais para o Ensino Médio. Diário Oficial da União, Poder Executivo, Brasília, DF, 24 jan. Seção 1, p. 10. 2011.

DAYRREL, D. CARRANO, P. Juventude e ensino médio: Quem é este aluno que chega à escola? In: DAYRELL, J.; CARRANO, P.; MAIA, C.L. (Orgs.) Juventude e ensino médio: sujeitos e currículos em diálogo. Belo Horizonte: Editora UFMG, 2014.

GOODSON, I. F. La construcción social del currículum. Posibilidades y ámbitos de investigación de la historia del currículum. Revista de Educación, num. 295, págs. 7-37. 1991.

LIMA, E.S. OLIVEIRA, A.D. As contribuições da pesquisa em educação para a produção de conhecimentos no semiárido. In.: (Orgs) SOUSA E SILVA; C.M.; SOUZA LIMA, E.; CANTALICE, M.L.; ALENCAR, M.T.; LOPES DA SILVA, W.A.. INSA Semiárido Piauiense: Educação e Contexto. Campina Grande, 2010.

MOREIRA, R.J. Ruralidades e globalizações: ensaiando uma interpretação. In: MORIERA, Roberto J. et al. (Orgs.). Identidades sociais: ruralidades no Brasil Contemporâneo. Rio de Janeiro: DP\&A. 2005.

OLIVEIRA, A. D. Jovens no Semiárido Baiano: Experiências de Vida e Formação no Campo. Salvador, 2014. Dissertação (Mestrado em Educação e Contemporaneidade) - Universidade do Estado da Bahia. Salvador, 2014.

REIS, E.S. Educação do campo: Escola, currículo e contexto. Juazeiro: ADAC/UNEB - DCH III/NECPEC-SAB, 2011.

SACRISTÁN, J G. Prólogo. In: STENHOUSE, L. Investigación y desarrollo del curriculum. Morata, Madrid, 1991.

SOUZA, E.C. A arte de contar e trocar experiências: reflexões teórico-metodológicas sobre história de vida em formação. Revista Educação em Questão, Natal, v. 25, n. 11, p. 22-39, jan./abr. 2006.

STENHOUSE, L. La investigación como base de la enseñanza. Aportes de L. Stenhouse a la reflexión sobre currículo. Reflexiones Pedagógicas, n. 21, diciembre, 2003.

SUÁREZ, D.H. Currículum, escuela y cultura. Elementos para repensar la teoría curricular. In.: TELLEZ, Magaldy. (Comp.). Otras miradas, otras voces. Repensando la educación en nuestros tiempos. Novedades Educativas, Buenos Aires, 2000.

et al. La documentación narrativa de experiencia pedagógica: Uma estratégia para la formación docente. Ministério de Educación, Ciência e Tecnologia, AICD: Buenos Aires, 2005. 


\section{RESUMO}

O presente texto centra-se nas discussões sobre apropriação do currículo pela experiência de docência no ensino médio em territórios rurais. Aproxima o debate sobre a constituição de um ensino médio desenvolvido nos territórios rurais em que sobressaem as experiências pedagógicas e curriculares dos professores. Diante do exposto o objetivo central é compreender como os sujeitos/docentes dão sentido as suas experiências pedagógicas no processo de apropriação e deslocamento curricular. Propomos como problema central a seguinte questão: Como são construídas narrativamente as experiências pedagógicas e curriculares dos docentes do Ensino Médio ofertado em territórios rurais? É uma pesquisa de enfoque qualitativo, que toma como princípio a abordagem (auto)biográfica (SOUZA, 2006) aliada as perspectivas da etnografia na educação (ANDRE, 2012). Utilizamos a observação e documentação narrativa de experiência pedagógica (SUÁREZ, 2005) como dispositivos de recolha das narrativas dos sujeitos, onde os professores poderão contar a experiência de levar à prática uma proposta curricular em "trânsito". Para analisar, as narrativas, elegemos a triangulação de fontes vinculada aos princípios da hermenêutica. É uma pesquisa em andamento, na qual pode-se apontar como breves análises a dinâmica de desenvolvimento de um currículo e experiências pedagógicas centradas na perspectiva da cidade, realizada em áreas rurais.

Palavras -chave: Currículo - Documentação Narrativa - Ensino médio.

\section{PEDAGOGICAL EXPERIENCES OF A CURRICULUM IN MOVEMENT IN MIDDLE SCHOOL IN RURAL TERRITORY \\ ABSTRACT}

The present text focuses on the discussions about the appropriation of the curriculum by the teaching experience in secondary education in rural territories. It approximates the debate about the constitution of a secondary education developed in the rural territories in which the pedagogical and curricular experiences of the teachers excel. In view of the above, the central objective is to understand how the subjects / teachers give meaning to their pedagogical experiences in the process of appropriation and curricular displacement. We propose as a central problem the following question: How are the pedagogical and curricular experiences of high school teachers offered in rural territories narratively constructed? It is a qualitative research that takes as a principle the (auto) biographical approach (SOUZA, 2006) allied with the perspectives of ethnography in education (ANDRE, 2012). We use observation and narrative documentation of pedagogical experience (Suárez, 2005) as devices for collecting subjects' narratives, where teachers can tell the experience of putting into practice a curricular proposal in "transit". To analyze the narratives, we chose the triangulation of sources linked to the principles of hermeneutics. It is a research in progress, in which one can point out as brief analyzes the development dynamics of a curriculum and pedagogical experiences centered on the perspective of the city, carried out in rural areas.

Keywords: Curriculum - Narrative Documentation - High school.

Submetido em Abr./2017

Aceito em Set./ 2017 